\title{
Sociotechnical probabilistic risk modeling to predict injurious falls in community living centers
}

\author{
Gail Powell-Cope, PhD, ARNP, FAAN; ${ }^{1 *}$ Robert Campbell, PhD, JD; ${ }^{2}$ Bridget Hahm, MA, MPH; ${ }^{1}$ Tatjana \\ Bulat, MD; ${ }^{3}$ John Westphal, BS ${ }^{4}$ \\ ${ }^{1}$ Department of Veterans Affairs Health Services Research and Development Center of Innovation on Disability and \\ Rehabilitation Research, ${ }^{2}$ Research and Development Service, and ${ }^{3}$ Veterans Integrated Service Network 8 Patient \\ Safety Center of Inquiry, James A. Haley Veterans’ Hospital, Tampa, FL; ${ }^{4}$ Outcome Engenuity, Plano, TX
}

\begin{abstract}
The goal of this study was to apply sociotechnical probabilistic risk assessment to prioritize risks and prevention strategies for serious injurious falls of residents in nursing homes. Risk modeling teams consisted of 26 clinical and nonclinical staff from three Department of Veterans Affairs community living centers and one state Veterans' nursing home. Participants met in groups several times to identify and assign probabilities to provider and resident at-risk behaviors and equipment failures. They identified prevention strategies for the failures that accounted for the highest levels of risk. Six scenarios were modeled: (1) transferring from bed to wheelchair, (2) propelling from bedside to bathroom, (3) transferring from wheelchair to toilet, (4) transferring from toilet to wheelchair, (5) propelling from bathroom to bedside, and (6) transferring from wheelchair to bed. The greatest paths of risk were for residents with impaired mobility and high fragility. A $26 \%$ reduction in injurious falls could be achieved by (1) reducing the number of unassisted transfers through a modest improvement in response time to alarms, (2) installing automatic brake locks on $90 \%$ of wheelchairs, (3) making the wheelchair maintenance process highly reliable, and (4) decreasing improper transfer techniques by $10 \%$.
\end{abstract}

Key words: community living centers, equipment failure, fall risk, fractures, injurious falls, injury prediction, nursing home, patient falls, risk modeling, wheelchair.

\section{INTRODUCTION}

Despite decades of research, serious fall-related injuries continue to occur in nursing homes, where the majority of the population is at risk of falling. While falls are very common in older adults, serious fall-related injuries are relatively rare events, occurring in only 11 percent of falls [1-4]. Between 3 and 17 percent of falls result in injury and from 3 to 6 percent result in fractures in nursing homes [5]. Residents of community living centers (CLCs) are four times more likely to experience hip fractures than older adults residing in the community [6], although more recent data show somewhat lower rates of hip fractures, especially in the Veterans Health Administration (VHA) CLC population, which is predominantly composed of men [7].

\footnotetext{
Abbreviations: AGS = American Geriatrics Society, CLC = community living center, ST-PRA = sociotechnical probabilistic risk assessment, VA = Department of Veterans Affairs, VHA = Veterans Health Administration.

*Address all correspondence to Gail Powell-Cope, PhD, ARNP, FAAN; Health Services Research and Development Center of Innovation on Disability and Rehabilitation Research (CINDRR), James A. Haley Veterans' Hospital, Grand Oak Plaza, 8900 Grand Oak Cir (118M), Tampa, FL 33637; 813-558-3911; fax: 813-558-3990.

Email: Gail.Powell-Cope@va.gov

http://dx.doi.org/10.1682/JRRD.2015.08.0165
} 
Pohl et al. conducted a prospective longitudinal study over $5 \mathrm{yr}$ to examine the incidence of fall recurrence among persons aged 75 to $93 \mathrm{yr}$ residing in the community $(N=230)$ [8]. Results indicated that 30 percent of participants had an injurious fall and had a significantly higher risk for having other injurious falls during the study period (hazard ratio 2.78; 95\% confidence interval 1.40-5.50).

Prospective research designs to predict serious fallrelated injuries or test interventions are limited by the lack of statistical power because these studies require very large sample sizes and are cost-prohibitive. While retrospective research designs using administrative data allow for large sample sizes, these data fail to capture the richness of clinical practice and human behaviors that contribute to risk. The factors independently associated with a fall-related serious injury to nursing home residents included (1) cognitive impairment or dementia because of higher fall rates, (2) presence of at least two chronic conditions, (3) balance and gait impairment, (4) low body mass index, and (5) female sex [9]. Risks for injurious falls are higher in ambulatory nursing home residents when compared with nonambulatory, bed-bound residents [10].

Researchers have found relationships between certain factors related to an older population and fall risk. For example, prospective and case-control studies have indicated that there is a 20 to 40 percent reduction in hip fractures in persons who engaged in physical activity compared with persons who were sedentary $[1,11]$. In a cohort study with a 1 yr follow-up, Klenk et al. studied the relationship between physical activity and falls in 1,214 persons aged $65 \mathrm{yr}$ and older who resided in the community [12]. These researchers found that there was a significant association between falls per $100 \mathrm{~h}$ walked and between falls and low activity, but no significant association between falls and average daily physical activity. Ward et al. conducted a longitudinal 4 yr prospective study of older community-dwelling persons and found that fall history and a slow chair stand functional performance revealed an incidence of 46 percent of injurious falls over a $2 \mathrm{yr}$ period [13].

Predicting serious fall-related injuries is a critical first step to reduce risk among vulnerable CLC residents. Conditions associated with fractures include (1) age over $85 \mathrm{yr}$; (2) agitated behavior; (3) use of a wheelchair, cane, or walker; (4) medications, including anticonvulsants, antidepressants, opioids, iron supplements, bisphosphonates, thiazides, and laxatives; and (5) polypharmacy [14-15]. Polypharmacy has been implicated in injurious falls in older adults who reside in a community, although randomized controlled trials are lacking to provide conclusive evidence [16].

In a 12 mo prospective study involving 149 community-dwelling participants aged 70 to $80 \mathrm{yr}$, Davis et al. developed linear mixed models that indicated mild cognitive impairment and fall status were significant in predicting future decline in mobility [17]. Van Doorn et al. gathered prospective data over a 2 yr period from 2,015 persons aged $65 \mathrm{yr}$ and over from 59 randomized nursing homes [18]. Researchers found that if a resident had dementia the unadjusted fall rate was 4.05 falls per year compared with 2.33 falls per year for residents without dementia $(p<0.001)$.

The importance of a thorough fall-risk factor assessment and of interventions to prevent or mitigate falls that are tailored to an older person's abilities cannot be overstated [19]. Multimodal interventions, such as gait and balance training, appropriate use of assistive devices, staff education, and medication modification for fall prevention in CLCs, have been advocated by the American Geriatrics Society (AGS), the British Geriatrics Society, and the American Academy of Orthopedic Surgeons' Panel on Falls Prevention, although the AGS guideline is primarily for older adults living in a community rather than in nursing homes [20-21]. Based on a systematic review, Cameron et al. found that multifactorial interventions in nursing homes may result in decreased falls and fall risk, although the evidence was not conclusive [22].

Clear guidance does not exist for specifying the right combination or dose of interventions to adequately protect specific at-risk populations, such as CLC residents with dementia or osteoporosis. Jensen et al. conducted a cluster randomized trial $(N=439)$ providing an $11 \mathrm{wk}$ program on fall prevention that was general and residentspecific in the intervention group and used no program in the control group [23]. In the 34 wk follow-up, 44 percent of those receiving the intervention suffered injurious falls compared with 56 percent in the control group. Kannus et al. stressed the importance of selecting the right interventions (e.g., vitamin supplements, hip protectors) for the residents who were most likely to benefit from the intervention(s) [24].

Staff education about fall prevention and resident fall-risk assessment and reassessment are standard practices, but the specificity and combination of fall prevention and injury protection interventions are not standardized [25]. Because not all falls in CLCs result in injuries, there has been a shift away from fall prevention to fall injury prevention. This new approach fits with the 
long-term care philosophy of promoting activity, avoiding chemical and mechanical restraints, and accepting therapeutic risk.

Although a plethora of studies has identified the relationships among falls and risk factors, determining how individual factors contribute to an overall estimate of fall risk is a relatively novel approach. The risk of falling increased in a cohort of elderly persons living in a community, from 8 percent among those with no risk factors to 78 percent among those with four or more risk factors [4]. A large study analyzed more than 70,000 falls in German nursing homes. Serious falls (requiring transfer to a hospital) were associated with increasing age, being female, less restricted functional status, walking (rather than transfers), and morning hours (specifically 6-8 a.m.) [26]. The Web-based Fall-Risk Assessment Tool is an ontology that is based upon a risk assessment algorithm and probability contributions for individual risk factors [27]. Probabilities may be extrapolated from odds ratios, and rules are developed for each risk factor. Some observed factors associated with injurious falls are modifiable, and it is possible that targeted interventions could result in decreased risk of injury from a fall.

The short-term goal of the present study was to proactively identify and prioritize risks for injurious falls in CLC residents. Key research questions were as follows:

1. What behaviors (in providers and patients), organizational structures and processes, and technology most contributed to serious injurious falls in CLCs?

2. What was the estimated contribution of risk for each behavior, structure and process, and technology?

3. Which behaviors most influenced risk in the model?

\section{METHODS}

This 18 mo project used sociotechnical probabilistic risk assessment (ST-PRA) methodology to build a model for assessing and quantifying the risk of serious injurious falls in CLCs. This methodology was conceptualized into five sequential phases (Table 1). With an approach to modeling risk that integrates human error into the risk assessment, ST-PRA is an established method in the fields of technology and engineering and has been applied to high-risk, high-reliability industries, such as aerospace, aviation, municipal waste disposal, and nuclear power [28-31]. In healthcare, it has been applied to anesthesia, medication errors, transition of care, hospital discharge, and organ transplantation [32-34].
Described as a hybrid between traditional decision support models and process analysis techniques (e.g., rootcause analysis, failure modes, effects analysis), ST-PRA was designed to address rare adverse events associated with high mortality and high costs in instances where traditional research methods have not captured the behavioral and technological aspects of risk [35].

Our study was well suited for ST-PRA because serious injurious falls in CLCs are relatively rare and result from multiple breakdowns in systems of care, including policy, processes, and human and technology failures. Because human factors affect healthcare delivery throughout patient care, the innovative adaptation of STPRA to the healthcare industry can be a powerful tool for improving patient safety.

\section{Sample}

Staff members $(n=26)$ from three VHA CLCs and from one state Veterans' CLC participated in a series of four to five structured focus groups over a 6 mo period. One facility ( $n=5$ staff members) did not obtain the necessary approvals in time to participate in risk-modeling team meetings with participants from the other study sites. Those participants instead attended a $1 \mathrm{~d}$ focus group to provide feedback on the models for validation purposes. Participants included housekeepers, nursing assistants, nurse practitioners, registered and licensed practical nurses, pharmacists, kinesiotherapists, and physical and recreational therapists.

The CLC populations ranged from 120 to 230 residents. Three facilities had short- and long-stay residents, one had short-stay and rehabilitation residents, and one had only long-stay residents. Purposive sampling was used to recruit staff from a variety of disciplines, shifts, and experience levels to ensure that the risk-modeling team was able to model the fall injury risks as thoroughly as possible. We asked supervisors to nominate staff for participation, and we sent a recruitment letter to each potential participant.

\section{Data Collection Procedures}

Using the ST-PRA approach, we (1) gathered information about fall-related injuries from the literature and from pilot work; (2) conducted discipline-specific focus groups (e.g., clinicians, support staff) to identify six clinical situations representing fall injury risk and mapped out initial paths of risk in fault tree formats; (3) used a mixeddiscipline focus group of selected participants $(n=9)$ to refine fault trees, estimate probabilities for events within 
Table 1.

Overview of sociotechnical probabilistic risk assessment methodology model.

\begin{tabular}{|c|c|c|}
\hline Phase & Brief Overview & Group Involved \\
\hline 1 & $\begin{array}{l}\text { Conduct initial data gathering to identify errors and their rates, at-risk } \\
\text { behaviors and their rates, equipment failures and their rates, and other } \\
\text { risk factors. }\end{array}$ & $\begin{array}{l}\text { Research team in preparation for risk-modeling team } \\
\text { meetings. }\end{array}$ \\
\hline 3 & $\begin{array}{l}\text { Refine fault trees; estimate the probabilities for human error, at-risk behav- } \\
\text { ior, and equipment failure rates; identify reduction strategies; and com- } \\
\text { pare them to risk management data from participating nursing homes. }\end{array}$ & $\begin{array}{l}\text { Core risk-modeling team during face-to-face meeting and } \\
\text { subteam meetings in video-conferences. }\end{array}$ \\
\hline 4 & Gain consensus. & All teams together in video-conferencing meetings. \\
\hline 5 & Update probabilistic model to include cost analysis. & Research team. \\
\hline
\end{tabular}

the fault trees, and identify potential risk-reduction strategies; and (4) gained consensus from all study participants. Model development was accomplished through an iterative and integrative process within and among focus groups. Relex (Crimson Quality LLC; Export, Pennsylvania) software was used to create prediction models.

We began by specifying an adverse outcome (i.e., serious fall-related injuries) and then identified and quantified each component or event and combination of events that lead to injury. The lists of precedent events were referred to as "failure paths." Once identified, the effects of failure paths were compared by attaching probability estimates to each path. Interventions were then identified and prioritized so that strategies would mitigate the highest failure risk combinations. The analysis was facilitated by visual representation of combinations of failure paths resulting in fault trees. Participants generally reached consensus quickly on the behaviors to model; choosing probabilities required discussions among participants and a higher level of facilitator involvement.

Focus groups were led by either the ST-PRA expert or an investigator. All focus groups were audiotape recorded, and the project manager took notes. Recordings and notes were used during analysis of meetings to make adjustments to the fault trees as needed. Another research team member ran the fault tree software and recorded the fault tree components synchronous with the discussions so that ongoing refinements could be made as participants reviewed the development of the trees.

\section{RESULTS}

During the first training meeting, study participants identified six clinical situations involving wheelchairs and unassisted transfers that the participants thought accounted for the greatest number of injurious falls in their CLCs. Six clinical situations were fully modeled and consisted of the following:

1. Transfer from bed to wheelchair.

2. Propulsion of a wheelchair from the bedside to the bathroom.

3. Transfer from wheelchair to toilet.

4. Transfer from toilet to wheelchair.

5. Propulsion of a wheelchair from the bathroom to bedside.

6. Transfer from wheelchair to bed.

Participants then agreed on five individual fall risk factors identified from the literature that accounted for the injurious falls: impaired mobility, functional impairment, cognitive impairment, medication effects, and postural hypotension [36].

The top-level event, "Resident incurs serious harm from fall," was defined as an injury due to a fall during an unassisted movement that required more than first aid (Figure 1). (For the purposes of this article, "event" is defined as a failure produced by the systems or contained within the system being modeled.) The serious injury was a function of the risk of falling from an unassisted movement and of likelihood of harm occurring during the fall. Each clinical situation model consisted of parallel branches to account for individual fall risk factors such as impaired mobility, functional impairment, impaired cognition, medication risk, and orthostatic hypotension.

The combined model consisted of 305,184 paths of risk (cut set reports). A path of risk was a combination of failures that led to a serious fall-related injury; every path of risk was unique. Estimated injury rates for the six clinical situations ranged from 0.2 percent per unassisted propulsion from bathroom to bedside to 2.0 percent per 


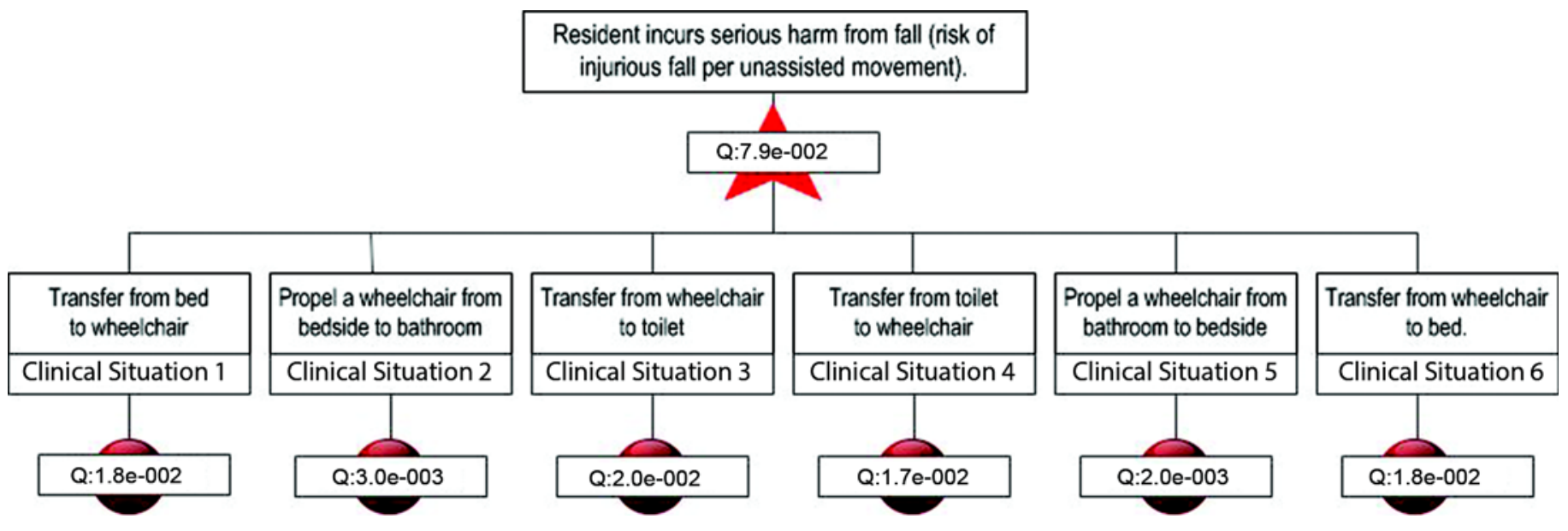

Figure 1.

Overall injurious fall risk modeled by six clinical scenarios involving unassisted wheelchair transfer or use. The Q number represents the probability of incurring a serious harm from a fall.

unassisted transfer from wheelchair to toilet. The four clinical situations involving transfers to and from a wheelchair accounted for 92 percent of the overall risk. The risks of an actual fall based on the individual risk factors were combined with the likelihood of harm during the fall. The combined risk of sustaining an injurious fall from the six movements modeled was 7.9 percent (of unassisted movements).

The risk of serious injury occurring from a fall was modeled based on the likelihood of a resident hitting an object or the floor. We considered the primary causal factors influencing the likelihood of harm to be presence or absence of protective measures (e.g., hip protectors, floor mats, helmet, padding of hard surfaces) and fragility, defined as presence or absence of osteoporosis (Table 2). When these variables were compared, protective measures reduced injury risk by 80 percent in residents with high fragility and by 90 percent in residents with low fragility. Even with protective measures in place, highly fragile residents were at nearly the same risk level as low-fragility residents without protective measures (6.0\% compared with $4.0 \%$, respectively). Combining fragility groups, the greatest reduction we could achieve was 81 percent. In other words, it was difficult to overcome the high fragility of residents. As one study participant (staff) stated about the very highest risk resident, "You might as well just go lay them down on the floor."
Table 2.

Estimates of injury risk.

\begin{tabular}{lccc}
\hline \multicolumn{1}{c}{ Fragility } & $\begin{array}{c}\text { No Protective } \\
\text { Measures (\%) }\end{array}$ & $\begin{array}{c}\text { Protective } \\
\text { Measure (\%) }\end{array}$ & Reduction (\%) \\
\hline Low & 40.0 & 4.0 & 90.0 \\
High & 30.0 & 6.0 & 80.0 \\
All Residents & 34.0 & 6.4 & 81.1 \\
\hline \hline
\end{tabular}

\section{Model Validity}

Two approaches were used to evaluate model validity. First, we compared model outputs to actual injurious fall rates as reflected in CLC quality improvement data. Study participants estimated that 21 serious injurious falls typically occurred across the three CLCs over a period of 1 yr. We then asked study participants to estimate four parameters of the model, including number of residents at risk, the number of movements increasing risk (i.e., transfers and propulsion to and from bathroom) per resident per day, and the proportion of unassisted movements. Estimates were developed for each clinical situation, and these estimates were used to calculate the predicted number of injurious falls for each situation (Table 3). The sum of these predicted rates across the six clinical situations was 357.7, representing the total potential injuries. While this total predicted rate seems high, this estimate represented the number of potential fall-related injuries we could see in the system. From this point, we used the Boolean logic to identify the actual number of fall-related injuries considering exposure to the risks of falls across the clinical situations. This piece of the modeling filtered 
Table 3.

Prediction of injurious fall rates from six clinical situations (CSs) modeled.

\begin{tabular}{|c|c|c|}
\hline CS & $\begin{array}{c}\text { Potential Injurious } \\
\text { Falls Predicted }\end{array}$ & $\begin{array}{c}\text { Actual Injurious } \\
\text { Falls Predicted }\end{array}$ \\
\hline Transfer from Wheelchair to Toilet (CS3) & 100.6 & 7.9 \\
\hline Transfer from Wheelchair to Bedside (CS6) & 83.7 & 6.6 \\
\hline Transfer from Toilet to Wheelchair (CS4) & 73.9 & 5.8 \\
\hline Propelling Wheelchair from Bedside to Bathroom (CS2) & 10.9 & 0.9 \\
\hline
\end{tabular}

out the same resident falling in two different places at the same time. The fault tree analysis calculated an overall risk of 7.9 percent (Figure 1). Multiplying 357.7 potential events by 0.079 yielded 28.3 injurious falls, hence the difference in predicted rates of 357.7 potential serious injurious falls versus 28.3 actual serious injurious falls. The six clinical situation models predicted a total of 28 serious injurious falls at the three participating VHA facilities compared with the actual reported rate of 21, which demonstrates evidence of model validity. Second, as a measure of content validity, we obtained feedback on the final model from a group of staff who were not in a modeling group. We presented the models to these staff, and they agreed with the choice of clinical situation, the relative risk of each clinical situation, and the probabilities assigned to key failures.

\section{Greatest Paths of Risk}

For clinical situations 1, 2, 4, and 5, the greatest path of risk to predicted serious injurious falls was a resident having impaired mobility and high fragility and coming into contact with an object (e.g., toilet or bedside dresser) during the fall and having no protective measures in place. For clinical situation 3, the greatest path of risk was a resident having either functional impairment or a medication risk combined with high fragility coming into contact with the floor during the fall and having no protective measures in place.

For clinical situations 1, 2, 3, and 4, the cut set paths (Figure 2) outlined a resident who attempted a wheelchair transfer unassisted because of a staff person not responding to an alarm within 1 min (i.e., staff at-risk behavior) because the staff person was working with another resident and a coworker failed to assist (i.e., staff at-risk behavior). Additionally, either the resident used the wheelchair as a brace (i.e., resident behavioral

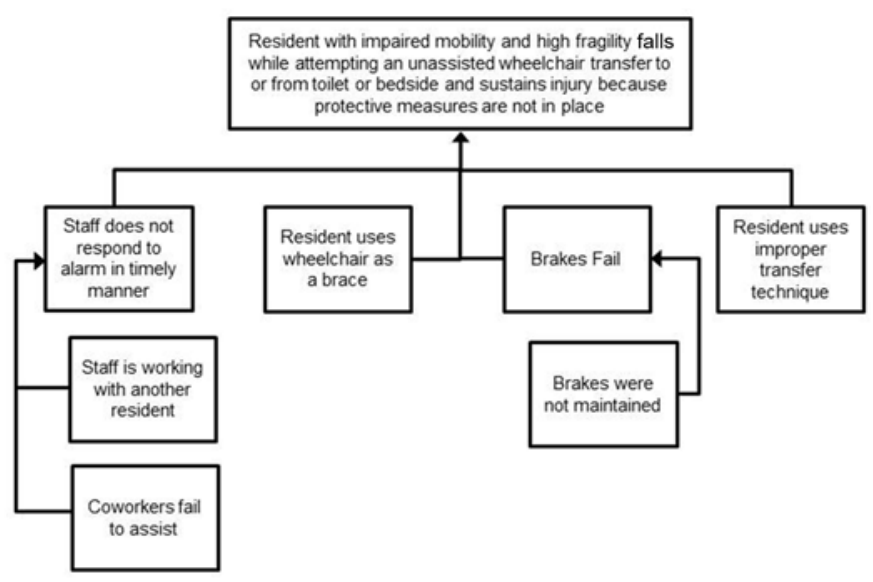

Figure 2.

Cut set report (paths of risk) revealed by modeling a clinical situation involving the greatest amount of risk of falling for residents of community living centers.

choice) and the brakes failed because of poor maintenance (i.e., technology failure combined with systems failure) or the resident used improper transfer techniques (i.e., resident behavioral choice). Causal factors and the absence of protective measures resulted in a fall with injury due to contact with an object.

Factors that were modeled but did not significantly affect risk consisted of the following: type and condition of flooring, type and use of footwear, absence of any conditional factor, wheelchair conditions other than brake failure (e.g., leg rests removed), improper positioning of wheelchair, and improper use of grab bars. For clinical situation 5 , the cut set path identified a resident who attempted to propel a wheelchair unassisted because of a staff person not responding to an alarm within $1 \mathrm{~min}$ because the staff member was working with another resident and a coworker failed to assist. Additionally, the resident improperly 
positioned him- or herself in the wheelchair and, while propelling it, slid out of it.

\section{Sensitivity Analysis}

Sensitivity analysis was conducted for each clinical situation by estimating the potential effect of two mitigation strategies. First, we decreased the noncompliance rate of a coworker assisting with resident alarms from 50 to 30 percent. Second, we decreased the rate of staff not being able to seek assistance or not asking for assistance from 45 to 30 percent. For clinical situation 3, with these risk-mitigation strategies inserted into the model, the top-level risk decreased from 2.0 percent (for transfers from bed to wheelchair) to 1.9 percent. When examining the overall risk of the combined clinical situations, a 5.5 percent reduction in risk resulted in five fewer potential serious injurious falls and one actual predicted serious injurious fall in a $1 \mathrm{yr}$ period. Considering these complex models and the relatively rare occurrence of injurious falls, these relatively simple and inexpensive staff behavioral changes produced a favorable return.

\section{Mitigation of Risk}

To assess the effectiveness of proposed interventions, we modified basic event probabilities within the model clinical situations that were affected by the designed mitigation strategies. Through this sensitivity analysis, we determined that a 26 percent reduction in potential serious injurious falls could be achieved by three actions:

1. Reducing the number of unassisted transfers through a modest improvement in response time to alarms.

2. Improving wheelchair safety by installing automatic brake locks on 90 percent of wheelchairs and creating a highly reliable wheelchair maintenance process.

3. Decreasing improper resident transfer techniques by 10 percent.

Study participants then addressed these three actions by identifying specific strategies of technology use, process changes, systems changes, and behavioral changes (Table 4).

\section{DISCUSSION}

The ST-PRA was a robust method for identifying and quantifying multiple types of risks, stratified by individual risk factor from the literature, that contribute to serious fall injury risk in nursing homes (e.g., technology factors, systems factors, and at-risk behaviors and behavioral choices of staff and residents) [37]. Use of multiple domains resulted in realistic models with predictive ability that mirrored actual risk as evidenced by the congruence between model prediction and information on actual injurious falls obtained from quality improvement data. Common pathways of risk were identified across clinical situations that directed clinicians to focus attention and resources on residents who have impaired mobility and functional impairments and who perform unassisted wheelchair transfers. The model clinical situations suggested that significant risk reduction can be accomplished by reducing unassisted transfers; increasing timeliness of staff response to alarms; improving wheelchair maintenance processes; improving residents' ability to perform transfers; and using appropriate protective equipment, such as bedside floor mats, helmets, hip protectors, and cushions for sharp corners of furniture.

Key fall risk factors were accounted for by the choice of modeling patient transfers and by stratifying models on the key risk factors of impaired mobility, functional impairment, impaired cognition, medications, and orthostatic hypotension; it was beyond the scope of this research to account for all risk factors. The risk factors we chose to stratify in the models are some of the most important documented risk factors for falls [36,38-39]. Likewise, based on provider participant guidance, we only modeled six types of falls involving locations in which falls are most common in long-term care settings, that is, the bedroom and the bathroom during walking and transfers [26]. Our study findings are confirmed by a very recent analysis of nearly 18,000 falls among CLC residents in Germany, which showed that more than three-quarters of all falls occurred in the rooms or bathrooms of residents, while falls in other areas (hallways, dining rooms, or outside the facility) were less frequent. Sit-to-stand or stand-to-sit transfers were associated with a higher percentage of falls (42\%) than walking (35\%) [40]. It is possible that other types of falls, for example, those that occur in hospice populations near the end of life, have different risk factors, and therefore would have to be modeled separately. Additionally, our models did not address falls from bed or falls that occur outside of resident rooms and bathrooms.

While much of the literature on falls and fall injury prevention in nursing homes focuses on modifying resident risk factors, such as exercise programs to increase balance, strength, and endurance [41-42], there has been 
Table 4.

Goals and prevention strategies by the three common high-risk paths.

Prevention Strategy

Type of Strategy

1. Reduce the Number of Unassisted Transfers and Movements Through Improving Response Time to Alarms

Use effective paging system that facilitates communication among staff (e.g., hands-free).

Evaluate overall device alarms used on unit. If the false positive alarm rate was high, reduce number of alarms to ensure a heightened alertness to fall alarms.

Reduce false positives by using alarm systems that allow for adjusting sensitivities.

Use a surveillance system of alarms to ensure they are in proper working order (batteries, connections).

Use a staffing process to ensure peak movement times have adequate staffing (e.g., after mealtime, during shift change).

Review nurse documentation processes and, if necessary, redesign so that staff are closer to residents when charting (e.g., work stations in hallways, increasing number of mobile computers, “care-trackers”).

Increase percentage of residents at risk for falls who have bed alarms.

Increase percentage of wheelchair users at risk for falls who have alarms.

Create method to prevent residents from disconnecting alarms.

\section{Improve Safety of Wheelchairs}

Review wheelchair maintenance process for nursing homes for the following: (1) timeliness of filling work orders for maintenance, (2) preventive maintenance program in place, (3) regular inspection of wheelchair integrity that includes brakes.

Increase percentage of manual wheelchairs that have automatic brake locks.

\section{Improve Resident Transfer Techniques}

Ensure stand-and-pivot training is part of restorative program upon direction of therapy.

Implement protocols for initiating therapy referrals for stand-and-pivot training.

Use the "stand-and-pivot" script (recorded playback message that could be changed periodically).

Have staff say "zinger" aloud when transferring residents to reinforce proper technique (e.g., feet down, push up, go).

Make stand-and-pivot part of a weekly reminder. Make sure staff get message about importance of standand-pivot technique.
Technology/Behavior

Process/Behavior

Technology

Process

System

Technology/Process

Process

Process

Technology

Process

Technology

System

Process

Behavior

Behavior

Behavior a shift toward interventions that are multifactorial; this shift is justified by our model, which incorporated process and systems changes [43-46]. For the most part, study participants identified numerous low- or no-cost solutions to address risk factors and failures identified in the model.

In a 1 yr learning collaborative involving nine hospitals, Quigley et al. successfully tested a bundle of interventions on medical-surgical and mental health units to prevent falls and, thus, serious injuries [47-49]. One year following this multisite quality improvement project, the sustainability of the collaborative was evaluated and the collaborative was found to have positive outcomes [50].

While preventing injurious falls was the focus of this investigation, the model indicated that some residents were so frail that they would be injured whether or not protective measures were in place. Study findings indicated that, in highly fragile residents, a critical approach for preventing harm is to prevent the fall in the first place.
Data from the present study were from three CLCs, which may limit the generalizability of the findings. However, it was evident from discussions with the three facilities' teams that important similarities and differences in risks were evident across CLCs. For example, only one CLC had a locked dementia unit and only one CLC had a dedicated palliative care unit; three CLCs had subacute units. Thus, our model likely captured a range of types of residents found in CLCs. Additionally, staff at the CLC used for validation endorsed the models and conclusions drawn from the study, which lends a measure of external validity to our work. While the sample size was rather small, study participants represented a wide range of clinicians and nonclinicians who were very knowledgeable about falls in their facilities. Prolonged engagement with study participants may have assisted in offsetting the small sample size. 


\section{CONCLUSIONS}

The ST-PRA method is designed to model risks at the facility level. A major contribution of this study was in helping to develop and validate ST-PRA as (1) a process for modeling injurious fall risk and (2) a process that could model common risk clinical situations across multiple CLCs. Quantifying multiple factors provided the evidence base for identifying interventions to decrease risk for injurious falls in CLCs. Sections of the fault trees will be used to develop decision-making tools that clinicians can use to make choices about fall injury prevention for specific high-risk groups of residents. Future clinical trials will evaluate the effectiveness of these tools on resident outcomes.

\section{ACKNOWLEDGMENTS}

\section{Author Contributions:}

Study concept and design: G. Powell-Cope.

Acquisition of data: R. Campbell, B. Hahm.

Analysis and interpretation of data: G. Powell-Cope, R. Campbell, B. Hahm, T. Bulat, J. Westphal.

Drafting of manuscript: G. Powell-Cope.

Critical revision of manuscript for important intellectual content:

G. Powell-Cope, R. Campbell, B. Hahm, T. Bulat, J. Westphal.

Administrative, technical, or material support: B. Hahm, J. Westphal.

Study supervision: G. Powell-Cope.

Financial Disclosures: John Westphal is employed by Outcome Engenuity, a consulting company that provides training in highly reliable outcomes, root cause analysis, and workplace accountability. The authors have declared that no other competing interests exist.

Funding/Support: This material was based on work supported by the VA, VHA Office of Research and Development, Rehabilitation Research and Development Service (award E4459R).

Additional Contributions: The authors would like to acknowledge co-investigators Dr. Elizabeth Bass and Dr. Inez Joseph for their contributions to the study; site principal investigators Dr. Ron Schorr, Ms. Ellen Thatcher, and Ms. Jan Odell; transcriptionist Ms. Lee Augello; and study participants for the gracious gifts of their time and expertise. Institutional Review: This study was approved by the University of South Florida Institutional Review Board; the University of Florida Institutional Review Board; the Bay Pines VA Healthcare System Institutional Review Board; and the Research and Development Committees at the James A. Haley Veterans' Hospital, Bay Pines VA Healthcare System, and the North Florida/South Georgia Veterans Health System. Written informed consent was obtained from all staff and residents participating in the research.

Participant Follow-Up: The authors have no plans to notify the study subjects of the publication of this article because of a lack of contact information.

\section{REFERENCES}

1. Gregg EW, Pereira MA, Caspersen CJ. Physical activity, falls, and fractures among older adults: A review of the epidemiologic evidence. J Am Geriatr Soc. 2000;48(8):883-93. [PMID:10968291] http://dx.doi.org/10.1111/j.1532-5415.2000.tb06884.x

2. King MB, Tinetti ME. Falls in community-dwelling older persons. J Am Geriatr Soc. 1995;43(10):1146-54. [PMID:7560708] http://dx.doi.org/10.1111/j.1532-5415.1995.tb07017.x

3. Nevitt MC, Cummings SR, Kidd S, Black D. Risk factors for recurrent nonsyncopal falls. A prospective study. JAMA. 1989;261(18):2663-8. [PMID:2709546] http://dx.doi.org/10.1001/jama.1989.03420180087036

4. Tinetti ME, Speechley M, Ginter SF. Risk factors for falls among elderly persons living in the community. $\mathrm{N}$ Engl J Med. 1988;319(26):1701-7. [PMID:3205267] http://dx.doi.org/10.1056/NEJM198812293192604

5. Rubenstein LZ, Josephson KR, Osterweil D. Falls and fall prevention in the nursing home. Clin Geriatr Med. 1996; 12(4):881-902. [PMID:8890121]

6. Sugarman JR, Connell FA, Hansen A, Helgerson SD, Jessup MC, Lee $\mathrm{H}$. Hip fracture incidence in nursing home residents and community-dwelling older people, Washington State, 1993-1995. J Am Geriatr Soc. 2002;50(10): 1638-43. [PMID:12366616] http://dx.doi.org/10.1046/j.1532-5415.2002.50454.x

7. Quigley PA, Campbell RR, Bulat T, Olney RL, Buerhaus P, Needleman J. Incidence and cost of serious fall-related injuries in nursing homes. Clin Nurs Res. 2012;21(1):10-23. [PMID:21788448] http://dx.doi.org/10.1177/1054773811414180

8. Pohl P, Nordin E, Lundquist A, Bergström U, Lundin-Olsson L. Community-dwelling older people with an injurious fall are likely to sustain new injurious falls within 5 years-a prospective long-term follow-up study. BMC Geriatr. 2014; 14:120. [PMID:25407714] http://dx.doi.org/10.1186/1471-2318-14-120

9. Tinetti ME, Doucette J, Claus E, Marottoli R. Risk factors for serious injury during falls by older persons in the community. J Am Geriatr Soc. 1995;43(11):1214-21. [PMID:7594154] http://dx.doi.org/10.1111/j.1532-5415.1995.tb07396.x

10. Thapa PB, Brockman KG, Gideon P, Fought RL, Ray WA. Injurious falls in nonambulatory nursing home residents: A comparative study of circumstances, incidence, and risk factors. J Am Geriatr Soc. 1996;44(3):273-8.

[PMID:8600195] http://dx.doi.org/10.1111/j.1532-5415.1996.tb00913.x

11. Sherrington C, Whitney JC, Lord SR, Herbert RD, Cumming RG, Close JC. Effective exercise for the prevention of 
falls: A systematic review and meta-analysis. J Am Geriatr Soc. 2008;56(12):2234-43. [PMID:19093923]

http://dx.doi.org/10.1111/j.1532-5415.2008.02014.x

12. Klenk J, Kerse N, Rapp K, Nikolaus T, Becker C, Rothenbacher D, Peter R, Denkinger MD; ActiFE Study Group. Physical activity and different concepts of fall risk estimation in older people-Results of the ActiFE-Ulm study. PLoS ONE. 2015;10(6):e0129098. [PMID:26058056] http://dx.doi.org/10.1371/journal.pone.0129098

13. Ward RE, Leveille SG, Beauchamp MK, Travison T, Alexander N, Jette AM, Bean JF. Functional performance as a predictor of injurious falls in older adults. J Am Geriatr Soc. 2015;63(2):315-20. [PMID:25688606] http://dx.doi.org/10.1111/jgs.13203

14. Spector W, Shaffer T, Potter DE, Correa-de-Araujo R, Rhona Limcangco M. Risk factors associated with the occurrence of fractures in U.S. nursing homes: Resident and facility characteristics and prescription medications. J Am Geriatr Soc. 2007;55(3):327-33. [PMID:17341233] http://dx.doi.org/10.1111/j.1532-5415.2007.01081.x

15. Baranzini F, Diurni M, Ceccon F, Poloni N, Cazzamalli S, Costantini C, Colli C, Greco L, Callegari C. Fall-related injuries in a nursing home setting: Is polypharmacy a risk factor? BMC Health Serv Res. 2009;9(1):228.

[PMID:20003327] http://dx.doi.org/10.1186/1472-6963-9-228

16. Fried TR, O’Leary J, Towle V, Goldstein MK, Trentalange M, Martin DK. Health outcomes associated with polypharmacy in community-dwelling older adults: A systematic review. J Am Geriatr Soc. 2014;62(12):2261-72. [PMID:25516023] http://dx.doi.org/10.1111/jgs.13153

17. Davis JC, Best J, Hsu CL, Nagamatsu LS, Dao E, LiuAmbrose T. Examining the effect of the relationship between falls and mild cognitive impairment on mobility and executive functions in community-dwelling older adults. J Am Geriatr Soc. 2015;63(3):590-3. [PMID:25800907] http://dx.doi.org/10.1111/jgs.13290

18. Van Doorn C, Gruber-Baldini AL, Zimmerman S, Hebel JR, Port CL, Baumgarten M, Quinn CC, Taler G, May C, Magaziner J; Epidemiology of Dementia in Nursing Homes Research Group. Dementia as a risk factor for falls and fall injuries among nursing home residents. J Am Geriatr Soc. 2003;51(9):1213-8. [PMID:12919232] http://dx.doi.org/10.1046/j.1532-5415.2003.51404.x

19. Tinetti ME. Clinical practice. Preventing falls in elderly persons. N Engl J Med. 2003;348(1):42-9. [PMID:12510042] http://dx.doi.org/10.1056/NEJMcp020719

20. Panel on Prevention of Falls in Older Persons, American Geriatrics Society and British Geriatrics Society. Summary of the updated American Geriatrics Society/British Geriatrics Society clinical practice guideline for prevention of falls in older persons. J Am Geriatr Soc. 2011;59(1):148-57. [PMID:21226685]

http://dx.doi.org/10.1111/j.1532-5415.2010.03234.x

21. Vu MQ, Weintraub N, Rubenstein LZ. Falls in the nursing home: Are they preventable? J Am Med Dir Assoc. 2004; 5(6):401-6. [PMID:15530179] http://dx.doi.org/10.1097/01.JAM.0000144553.45330.AD

22. Cameron ID, Gillespie LD, Robertson MC, Murray GR, Hill KD, Cumming RG, Kerse N. Interventions for preventing falls in older people in care facilities and hospitals. Cochrane Database Syst Rev. 2012;12:CD005465. [PMID:23235623]

23. Jensen J, Lundin-Olsson L, Nyberg L, Gustafson Y. Fall and injury prevention in older people living in residential care facilities. A cluster randomized trial. Ann Intern Med. 2002;136(10):733-41. [PMID:12020141] http://dx.doi.org/10.7326/0003-4819-136-10-200205210$\underline{00008}$

24. Kannus P, Sievänen H, Palvanen M, Järvinen T, Parkkari J. Prevention of falls and consequent injuries in elderly people. Lancet. 2005;366(9500):1885-93. [PMID:16310556] http://dx.doi.org/10.1016/S0140-6736(05)67604-0

25. Quigley P, Bulat T, Kurtzman E, Olney R, Powell-Cope G, Rubenstein L. Fall prevention and injury protection for nursing home residents. J Am Med Dir Assoc. 2010; 11(4):284-93. [PMID:20439049]

26. Büchele G, Becker C, Cameron ID, König HH, Robinovitch S, Rapp K. Predictors of serious consequences of falls in residential aged care: Analysis of more than 70,000 falls from residents of Bavarian nursing homes. J Am Med Dir Assoc. 2014;15(8):559-63. [PMID:24825170] http://dx.doi.org/10.1016/j.jamda.2014.03.015

27. Cattelani L, Palumbo P, Palmerini L, Bandinelli S, Becker C, Chesani F, Chiari L. FRAT-up, a Web-based fall-risk assessment tool for elderly people living in the community. J Med Internet Res. 2015;17(2):e41. [PMID:25693419] http://dx.doi.org/10.2196/jmir.4064

28. Paté-Cornell E. Finding and fixing systems weaknesses: Probabilistic methods and applications of engineering risk analysis. Risk Anal. 2002;22(2):319-34. [PMID:12022679] http://dx.doi.org/10.1111/0272-4332.00025

29. Lonati G, Cernuschi S, Giugliano M, Grosso M. Health risk analysis of PCDD/F emissions from MSW incineration: Comparison of probabilistic and deterministic approaches. Chemosphere. 2007;67(9):S334-43. [PMID:17222443] http://dx.doi.org/10.1016/j.chemosphere.2006.05.139

30. United States Nuclear Regulatory Commission. Backgrounder on probabilistic risk assessment [Internet]. Washington (DC): U.S. Nuclear Regulatory Commission; 2016 Feb [updated 2016 Apr 8; cited 2016 Oct 13]. Available from: http://www.nrc.gov/reading-rm/doc-collections/factsheets/probabilistic-risk-asses.html 
31. Cullen AC. The sensitivity of probabilistic risk assessment results to alternative model structures: A case study of municipal waste incineration. J Air Waste Manag Assoc. 1995;45(7):538-46. [PMID:7634125] http://dx.doi.org/10.1080/10473289.1995.10467385

32. Martz H, Picard R. On comparing PRA results with operating experience. Reliab Eng Syst Saf. 1998;59:187-99. http://dx.doi.org/10.1016/S0951-8320(97)00138-5

33. Battles JB, Kanki BG. The use of socio-technical probabilistic risk assessment at AHRQ and NASA. In: Spitzer C, Schmocker U, Dang VN, editors. Probabilistic safety assessment and management, vol. 4. Berlin (Germany): Springer; 2004. p. 2212-7.

34. Comden SC, Marx D, Murphy-Carley M, Hale M. Using probabilistic risk assessment to model medication system failures in long-term care facilities. In: Henriksen K, Battles JB, Marks E, Lewin D, editors. Advances in patient safety: From research to implementation. Vol. 2: Concepts and methodology. Rockville (MD): Agency for Healthcare Research and Quality; 2005. p. 395-408.

35. Marx DA, Slonim AD. Assessing patient safety risk before the injury occurs: An introduction to socio-technical probabilistic risk modelling in healthcare. Qual Saf Health Care. 2003;12 Suppl 2:ii33-8. [PMID:14645893]

36. Rubenstein LZ, Josephson KR. The epidemiology of falls and syncope. Clin Geriatr Med. 2002;18(2):141-58.

[PMID:12180240] http://dx.doi.org/10.1016/S0749-0690(02)00002-2

37. Agency for Healthcare Research and Quality. Falls prevention literature review [Internet]. Rockville (MD): Agency for Healthcare Research and Quality; 2010 Feb [cited 2015 Aug 31]. Available from: https://archive.ahrq.gov/professionals/systems/long-term-care/resources/injuries/fallspxlitrev/index.html

38. Aranda-Gallardo M, Enriquez de Luna-Rodriguez $M$, Canca-Sanchez JC, Moya-Suarez AB, Morales-Asencio JM. Validation of the STRATIFY falls risk-assessment tool for acute-care hospital patients and nursing home residents: Study protocol. J Adv Nurs. 2015;71(8):1948-57.

[PMID:25778931]

http://dx.doi.org/10.1111/jan.12651

39. Álvarez Barbosa F, Del Pozo-Cruz B, Del Pozo-Cruz J, Alfonso-Rosa RM, Sañudo Corrales B, Rogers ME. Factors associated with the risk of falls of nursing home residents aged 80 or older. Rehabil Nurs. 2016;41(1):16-25.

[PMID:26399374]

http://dx.doi.org/10.1002/rnj.229

40. Becker C, Rapp K. Fall prevention in nursing homes. Clin Geriatr Med. 2010;26(4):693-704. [PMID:20934616] http://dx.doi.org/10.1016/j.cger.2010.07.004

41. Rosendahl E, Gustafson Y, Nordin E, Lundin-Olsson L, Nyberg L. A randomized controlled trial of fall prevention by a high-intensity functional exercise program for older people living in residential care facilities. Aging Clin Exp Res. 2008;20(1):67-75. [PMID:18283231]

http://dx.doi.org/10.1007/BF03324750

42. Schoenfelder DP, Rubenstein LM. An exercise program to improve fall-related outcomes in elderly nursing home residents. Appl Nurs Res. 2004;17(1):21-31. [PMID:14991552] http://dx.doi.org/10.1016/j.apnr.2003.10.008

43. Rapp K, Lamb SE, Büchele G, Lall R, Lindemann U, Becker C. Prevention of falls in nursing homes: Subgroup analyses of a randomized fall prevention trial. J Am Geriatr Soc. 2008;56(6):1092-7. [PMID:18482303] http://dx.doi.org/10.1111/j.1532-5415.2008.01739.x

44. Scott V, Donaldson M, Gallagher E. A review of the literature on best practices in falls prevention for residents of long-term care facilities [Internet]. Vancouver (Canada): BC Injury Research and Prevention Unit; 2003 May 8 [cited 2016 Oct 1]. 29 p. Available from: http://www.injuryresearch.bc.ca/wp-content/uploads/2003/05/LTC-lit-review.pdf

45. Rask K, Parmelee PA, Taylor JA, Green D, Brown H, Hawley J, Schild L, Strothers HS 3rd, Ouslander JG. Implementation and evaluation of a nursing home fall management program. J Am Geriatr Soc. 2007;55(3):342-9.

[PMID:17341235]

http://dx.doi.org/10.1111/j.1532-5415.2007.01083.x

46. Chang JT, Ganz DA. Quality indicators for falls and mobility problems in vulnerable elders. J Am Geriatr Soc. 2007; 55(Suppl 2):S327-34. [PMID:17910554] http://dx.doi.org/10.1111/j.1532-5415.2007.01339.x

47. Quigley PA, Barnett SD, Bulat T, Friedman Y. Reducing falls and fall-related injuries in medical surgical units: Oneyear multihospital falls collaborative. J Nurs Care Qual. 2016;31(2):139-45. [PMID:26323049] http://dx.doi.org/10.1097/NCQ.0000000000000151

48. Quigley PA, Hahm B, Collazo S, Gibson W, Janzen S, Powell-Cope G, Rice F, Sarduy I, Tyndall K, White SV. Reducing serious injury from falls in two veterans' hospital medicalsurgical units. J Nurs Care Qual. 2009;24(1):33-41.

[PMID:19092477]

http://dx.doi.org/10.1097/NCQ.0b013e31818f528e

49. Quigley PA, Barnett S, Bulat T, Friedman Y. Reducing falls and fall-related injuries in mental health: A one-year multihospital falls collaborative. J Nurs Care Qual. 2014;29(1): 51-9. [PMID:24275892] http://dx.doi.org/10.1097/01.NCQ.0000437033.67042.63

50. Neily J, Howard K, Quigley P, Mills PD. One-year followup after a collaborative breakthrough series on reducing falls and fall-related injuries. Jt Comm J Qual Patient Saf. 2005;31(5):275-85. [PMID:15960018]

Submitted for publication August 31, 2015. Accepted in revised form January 29, 2016. 
This article and any supplementary material should be cited as follows:

Powell-Cope G, Campbell R, Hahm B, Bulat T, Westphal J. Sociotechnical probabilistic risk modeling to predict injurious falls in community living centers. J Rehabil Res Dev. 2016;53(6):881-92.

http://dx.doi.org/10.1682/JRRD.2015.08.0165
ORCID: Gail Powell-Cope, PhD, ARNP, FAAN: 00000002-4608-0128; Robert Campbell, PhD, JD: 00000002-6269-9895; Bridget Hahm, MA, MPH: 0000-00017454-4471; Tatjana Bulat, MD: 0000-0002-4380-942X; John Westphal, BS: 0000-0001-6330-4712

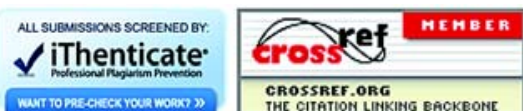

